\title{
Beach prediction experience to date: further development and review of the stream power-entropy approach
}

GI McPhail Water, Waste and Land Australia Pty Ltd, Australia

\begin{abstract}
Over the past 30 years, several methods for predicting the beaching characteristics of mineral processing tailings slurries have been developed; among these the stream power-entropy approach by the author. Although the initial development of the approach was completed in 1995, continued development and refinement has taken place since this date with its application to high-density slurries on a range of mining operations. Along the way, comparisons between the predicted and the measured beach profiles have been carried out as the beach slopes have developed and these comparisons have pointed the way to further development. This paper presents experience to date with the stream power-entropy approach highlighting the comparisons that have led to further refinement and the refinements implemented to both the approach, as well as laboratory tests and statistical approaches that have been developed to provide the required slurry data.
\end{abstract}

Keywords: tailings, beaching, stream power, entropy, beach slope, beach profile

\section{Introduction}

The history of the stream power entropy approach to beach modelling began in 1993 after funding for a series of large scale flume tests on tailings to understand the influence of slope, flow rate and other parameters on beaching behaviour was cancelled. This necessitated a change in thinking and direction. The wise words of three mentors came to mind. Dr Oskar Steffen mused while standing at a discharge on a tailings storage facility (TSF) some years previously that he was sure that beaching was all about energy. Dr George Annandale, a hydraulics engineer and a specialist in reservoir sedimentation, mentioned that a focus on stream power, a scalar parameter, would be more sensible than focusing velocity which is a vector and requires the consideration of direction in three principle axes. Finally, Professor Milton Harr of Purdue University said, on review of initial planning for the research, that the concept of entropy merited consideration given the high levels of variability and uncertainty associated with beaching. Serendipitously a reference by Kapur and Kesavan (1992) surfaced entitled Principles and Applications of Entropy and the concept of applying entropy to stream power was born (McPhail 1995).

Power is energy generated or consumed per unit of time. Stream power applied to beaching would be energy consumed by friction and viscous effects as a stream of slurry meanders down a beach after emerging from the inevitable plunge pool at the discharge point. But what is entropy? It is commonly used in chemistry and thermodynamics, but it came to further engineering practicality after Shannon (1948), an electrical engineer studying signal decay over distance, derived an equation to describe the decay rate that had the same equation as thermodynamic entropy. This equation is still used by electronic engineers today. Simply put, entropy is a measure of probabilistic uncertainty. Simply described, one can imagine a deck of playing cards. When a new pack is opened all the cards are arranged by suit (hearts, diamonds, clubs and spades) and in order from king to ace. As the cards are shuffled for a card game the cards are jumbled and the degree of order decreases. The probability of finding a card in a sequence decreases the more the cards are shuffled, i.e. the cards are becoming more randomly distributed. This increase in randomness is measured through the concept of entropy. The degree of entropy depends on how long, and the way in which, the cards are shuffled but will, at all times, tend to a maximum. This principle of entropy tending towards a maximum as the cards are shuffled (or a minimum if the cards are then re-ordered into suits and 
numbers) was captured by Jaynes (1957) who noted that entropy will tend to a maximum (or minimum) depending on the constraints set to the randomising (or ordering) process. What this principle does is expand the use of entropy suggesting that the entropy equation can be differentiated, and the resulting relationship set to zero, representing a maximum or a minimum in mathematical terms, and bringing another equation to bear.

Kapur and Kesavan (1992) note that it has been found that entropy and the principle of maximisation or minimisation of entropy applies to a great many natural phenomena. It was on this basis the process by the author of applying entropy to stream power, a measure of energy, began.

It was fortunate that, due to the interest in predicting beaching for unthickened and moderately thickened slurries being high in the 1980s, there was a good deal of information available, both at a small scale and at full scale, on beach measurements by Küpper (1991), Bentel (1981) and Thomson (1984), so it was possible to set about testing the potential of the stream power- entropy approach as part of the research without an extensive field and laboratory assessment. To fully establish the validity of the approach, however, field and laboratory assessments, especially for highly thickened slurries, are essential and are the subject of this paper.

It is important to recognise, however, that the science of beaching is not settled. There are several approaches to the matter of hydraulic deposition of tailings and beaching behaviour prediction, each with merit, and a wise practitioner considers a range of approaches during such times. This paper will demonstrate, however, that the stream power-entropy approach warrants serious consideration in any design where beach profiles are particularly important.

Before demonstrating the performance of the stream power-entropy approach over several current TSF operations it is necessary to first elaborate on the hypotheses postulated and tested in developing the approach as set out in the next section of this paper.

\section{$2 \quad$ Basics of the stream power-entropy approach}

The following hypotheses were tested and found to be valid in the course of developing the steam power-entropy approach:

1. It is energy that keeps particles in suspension in the flow stream.

2. The rate at which particles settle out of suspension is proportional to the rate of energy loss.

3. Stream power, i.e. energy per unit time, can be used to model energy variation because the average flow rate is approximately constant.

4. The beach profile and the hydraulic grade line are approximately parallel.

5. The most probable, least biased curve for the energy line can be estimated using entropy when applied to stream power under two physical constraints:

a. The beach has a finite length, $L$.

b. Since the rheology flow curve is a unique characteristic of each slurry, the shear stresses in the flow stream must lie on the rheology flow curve at equivalent shear rates.

6. Flow stops at the end of the beach, so the stream power is zero at this point. If the datum is set at the end of the beach, the energy line and the beach profile are congruent.

7. At the edge of the plunge pool at the discharge, the energy of the flow stream is dominated by the potential energy. Potential energy is proportional to the height drop down the beach so, per unit of gravitational force generated by the flow stream the stream power of the flow stream, in watts, is approximately equal to the height drop. 
Application of the above hypotheses to stream power using the entropy-based approach described by Kapur and Kesavan (1992) leads to the following equation:

$$
P(x)=-\frac{1}{\mu} \ln \left[\left(1-\exp ^{-\mu P_{0}}\right) \frac{x}{L}+\exp ^{-\mu P_{0}}\right]
$$

$P(x)$ is the stream power at a distance $x$ from the discharge. The parameter $P_{0}$ is the stream power at the start of the beach. $L$ is the distance from the start of the beach to the edge of the supernatant pond where the residual stream power will be dissipated and brought to zero. The parameter $\mu$ is a constant emerging from the mathematical derivation of Equation 3.

The slope at the start of the beach is obtained by differentiating Equation 3 with respect to $x$ to obtain $S_{0}$ which yields the following equation:

$$
S_{0}=-\frac{\left(1-\exp ^{-\mu P_{0}}\right)}{L \mu \exp ^{-\mu P_{0}}}
$$

It follows that a knowledge of the stream power at the start of the beach will enable the determination of $\mu$ from Equation 2. The initial steam power, $P_{0}$, in watts, is numerically equal to the height drop down the beach from the plunge pool to the end of the beach.

The slope of the stream power curve, $S_{B}(x)$ and hence of the beach can be determined at any point, $x$, along the beach from the equation:

$$
S_{B}(x)=-\frac{\left(1-\exp ^{-\mu P_{0}}\right)}{L \mu \exp ^{-\mu P(x)}}
$$

The elevation, $y$, of the beach at any point, $x$, along the beach can be determined using the following equation and working in small increments of $\Delta x$ from the start of the beach:

$$
y=y(x+\Delta x)+S_{B}(x) \Delta x
$$

Equation 4 gives the beach profile.

What the entropy approach tells us is that of all the ways that stream power can decay from the start of the beach to the end, the one defined by the above equations is the most probable, and least biased, based on the constraints that, the beach has a finite length, $L$, and that at each point down the beach the shear stress is equal to the shear stress derived from the rheological flow curve for the slurry. It is this latter constraint that closes the solution which is determined iteratively.

The application of Equations 1 to 4 requires the following information:

- The elevation of the beach at the start of the beach profile.

- The length of the beach.

- Slurry density.

- Slurry flow rate.

- Rheological flow curve.

It is this issue of the rheological flow curve measurement that presents the next challenge. 


\section{$3 \quad$ Rheology testing}

Mineral processing tailings slurries are most commonly described as yield pseudo-plastic which means that they express a yield stress at zero shear rate and that the curve of shear stress versus shear rate is non-linear. These parameters are indicated in Figure 1.

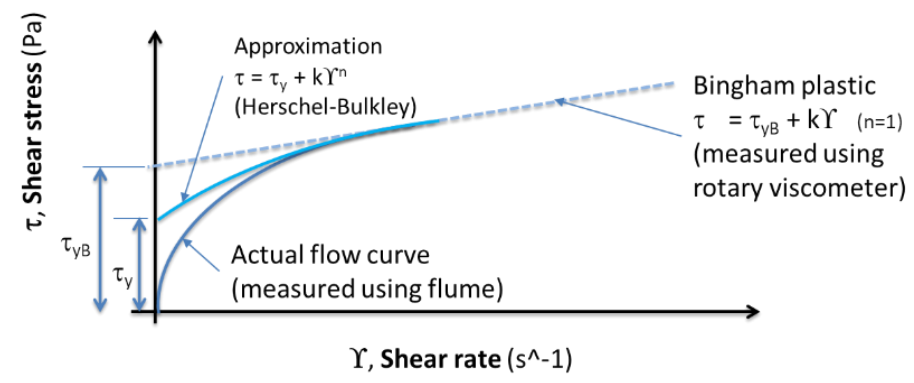

Figure 1 Typical flow curve for mineral processing tailings slurries

In engineering applications, the flow curve is usually approximated using two or three parameter equations such as the Bingham equation and the Herschel-Bulkley equation. However, the most common laboratory methods of determining the flow curve involve the use of rotary viscometers, all of which lose accuracy in the low shear rate ranges typical of beaching slurries. This is due to the effects of settling out of the slurry in the viscometer, as well as slippage as the viscometer rotates.

The author has overcome this limitation by developing a flume rheometer in which slurry is discharged down a narrow flume at a range of discharge rates, and the deposited profile is measured before the slurry flows past the end of the flume the moment discharge is stopped. One version of the flume is illustrated in Figure 2. The stream power-entropy equations are applied in conjunction with force-momentum flux equations to back-calculate the flow curves that produced the measured profiles. These curves are combined to yield the flow curve in the shear rate range of zero to $20 \mathrm{~s}^{-1}$, and then further combined with the rotary viscometer test results to develop the flow curve beyond $20 \mathrm{~s}^{-1}$ as illustrated by a typical result in Figure 2 . The flow curve is plotted in 'true shear rate' terms as would be derived from a rotary viscometer test. The flume rheometer yields 'bulk or wall shear rate' which is then converted to true shear rate using the Mooney-Rabinowitsch equation. When the true shear rate data is applied in full-scale predictions it is converted to bulk or wall shear rate again using the Mooney-Rabinowitsch equation.

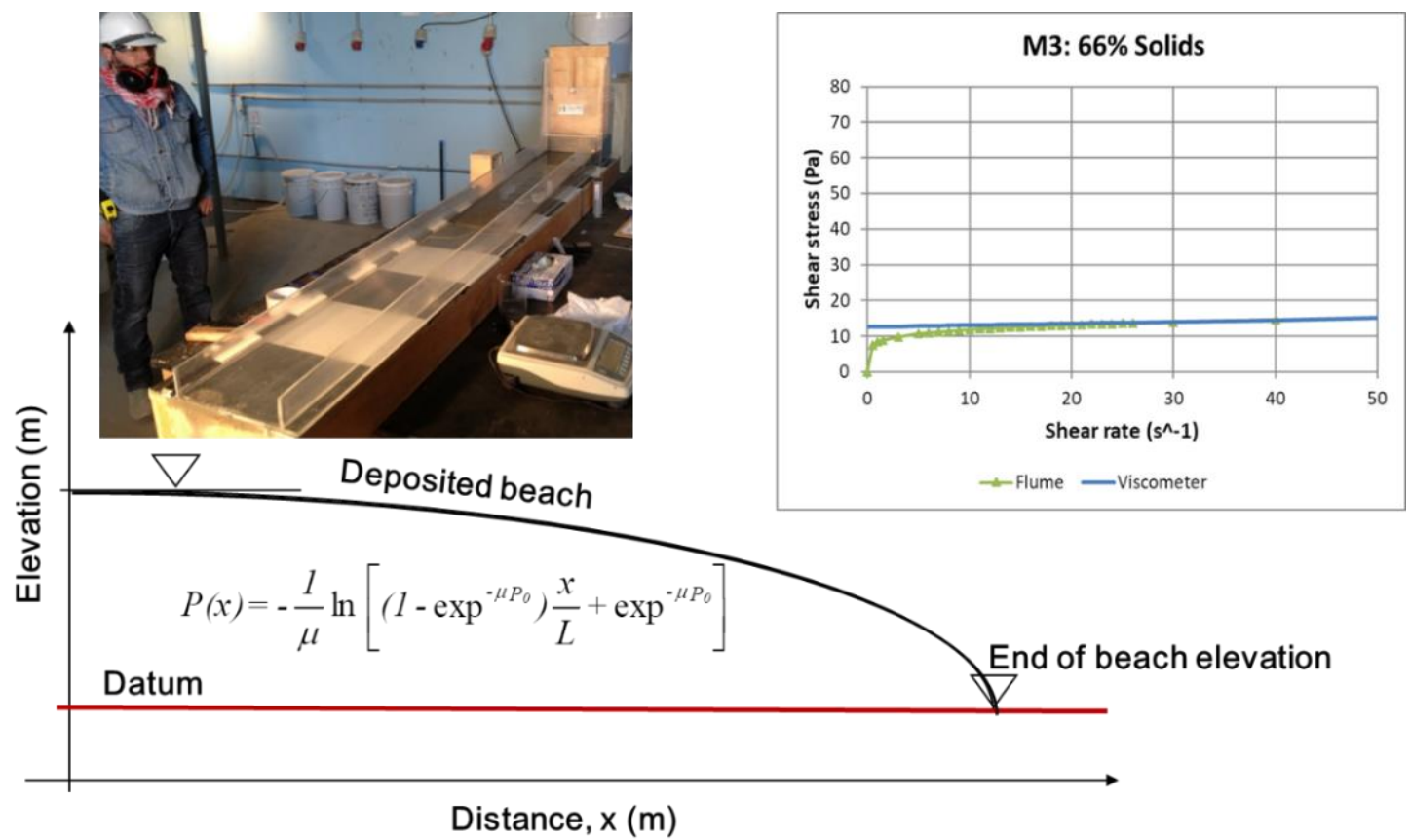

Figure 2 Typical flume rheometer and flow curve from laboratory testing 


\section{$4 \quad$ Verification of the stream power-entropy approach}

Verification of a beach modelling approach requires real field-scale data and while the stream power-entropy approach has been applied to some 30 projects in Africa, Australia, and North and South America, only a few have reached the stage of implementation that allows comparison between the model predictions based on measured rheology and field conditions. Two have been selected for this paper as together they provide a basis for ongoing development and refinement of the approach.

The first of these is Osborne Mine in Queensland, Australia where the tailings production rate was some 4,000 tpd and where full-scale beaches developed at a number of stages and at differing slurry consistencies were used to back-calculate the rheology using the same methodology as applied to flume rheometer tests and the back-calculated rheology compared with rotary viscometer data. This was described in Charlebois et al. (2013) which documented the full-scale beach profiles in Figure 3 and compared the back-calculated rheology with the rotary viscometer data in Figure 4.

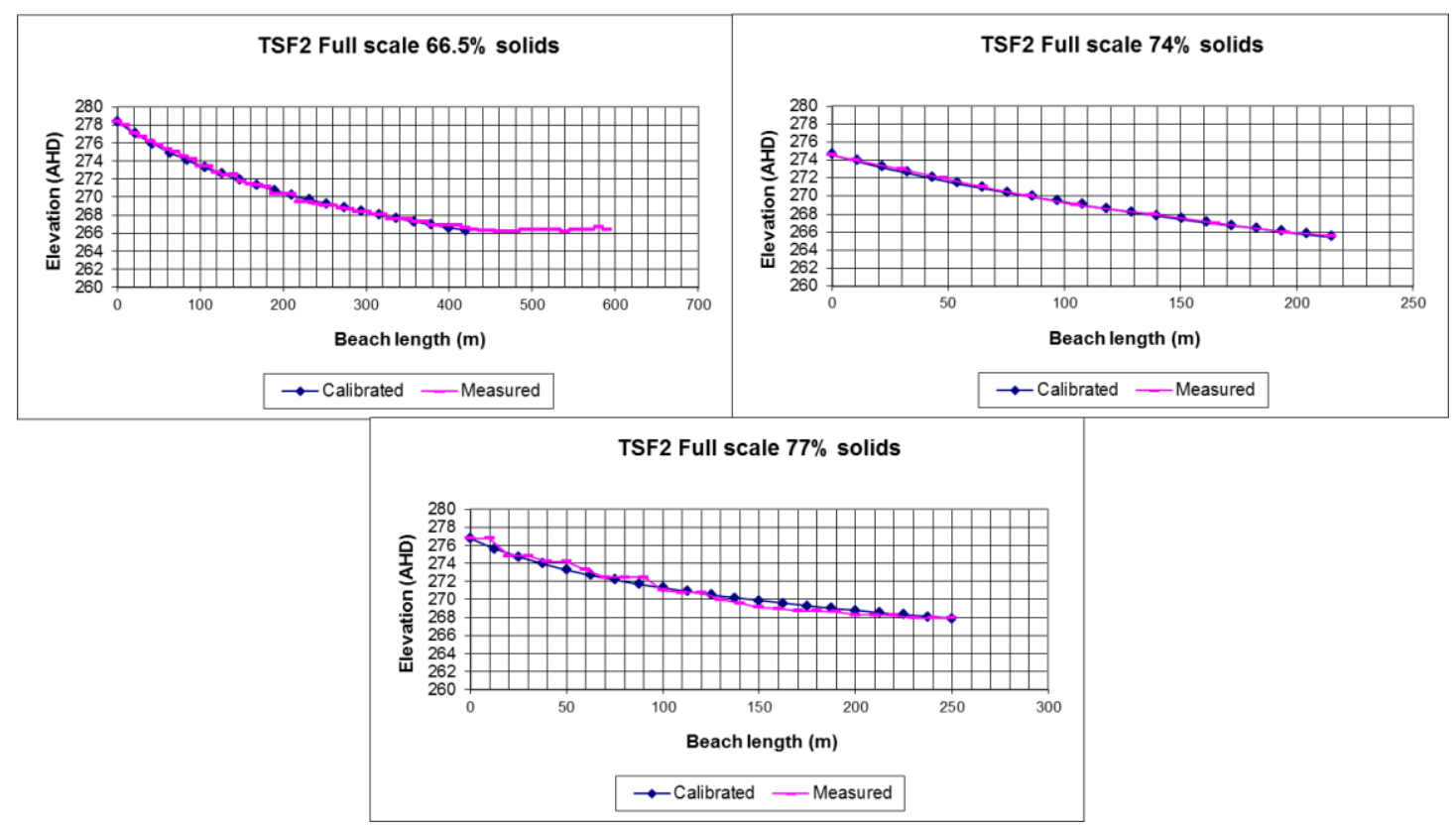

Figure 3 Osborne Mine beach profiles for a range of slurry consistencies

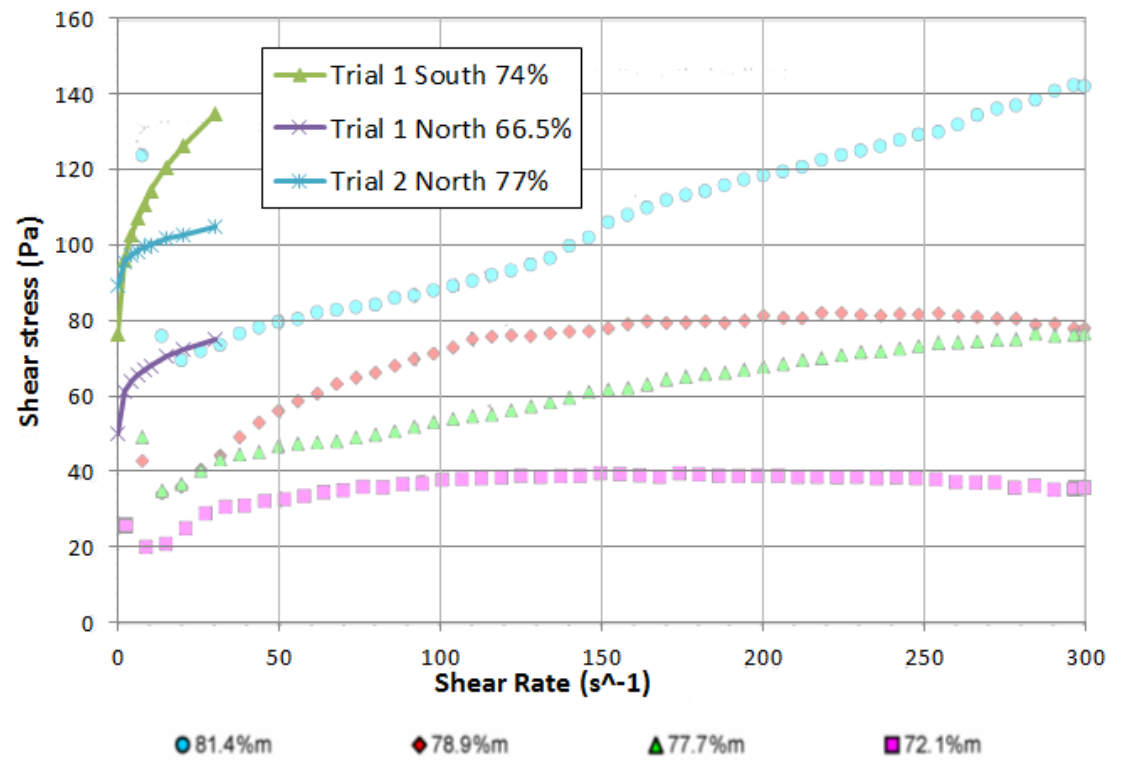

Figure 4 Back-calculated and rotary viscometer rheology 
It is evident from Figure 4 that the back-calculated rheology is much higher than the measured rheology, yet the slurry could be pumped with an ordinary centrifugal pump with mechanical seals. This seems incongruous.

The second comparison is from a beaching trial conducted at Centinela mine, Chile. To improve confidence in the beach predictions, Centinela opted to conduct a semi-industrial-scale trial in a 100 by $100 \mathrm{~m}$ paddock. Two single point discharges were set up with each one run on its own. Figure 5 shows the paddock discharge and the paddock geometry after the trial.
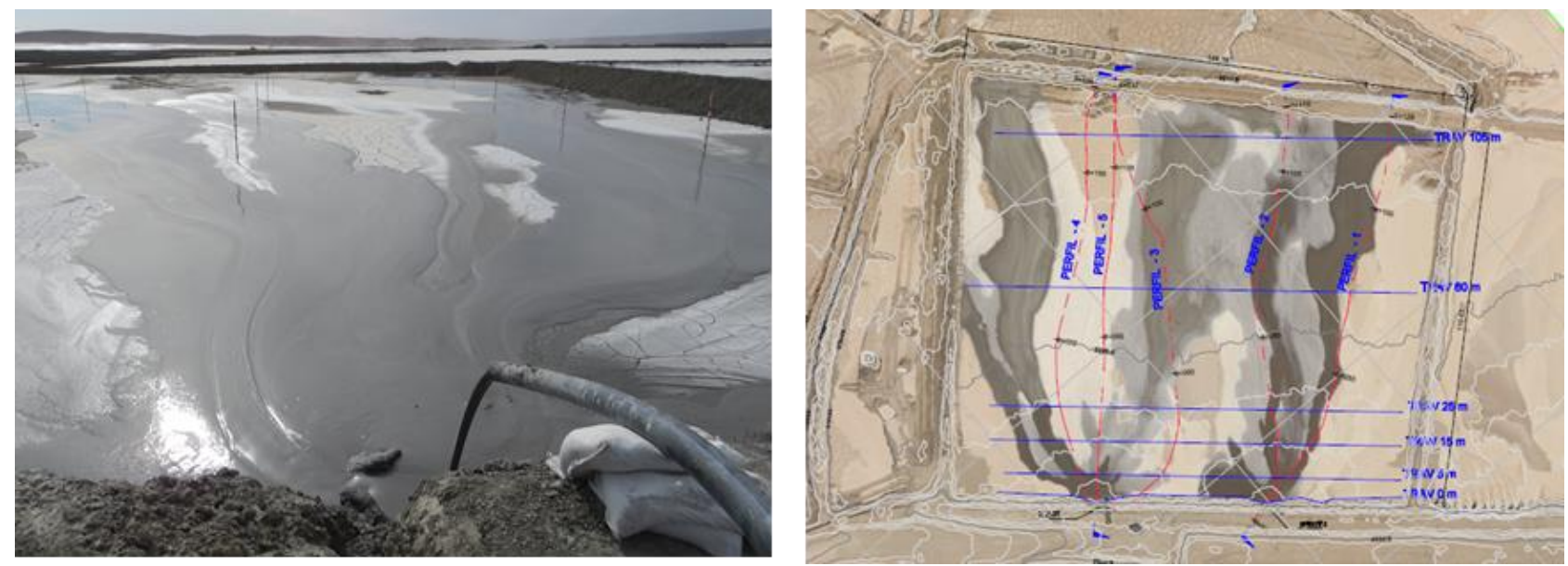

Figure 5 Semi-industrial-scale trial at Centinela mine

During the trial, there was significant variability in the discharged slurry characteristics, flow rates and tailings particle characteristics (Table 1). Table 2 shows the changes in beach profile over the course of the trial.

Table 1 Slurry and tailings characteristics during the Centinela trial

\begin{tabular}{lllllll}
\hline & $\begin{array}{l}\text { \% solids } \\
(\% \mathbf{w} / \mathbf{w})\end{array}$ & $\begin{array}{l}\text { Viscosity } \\
(\mathbf{P a} \text { s) }\end{array}$ & $\begin{array}{l}\text { Bingham yield } \\
\text { stress }(\mathbf{P a})\end{array}$ & $\begin{array}{l}\mathbf{P}_{\mathbf{8 0}} \\
(\boldsymbol{\mu m})\end{array}$ & $\begin{array}{l}\text { Specific gravity } \\
\text { solids }\left(\mathbf{t} / \mathbf{m}^{3}\right)\end{array}$ & $\begin{array}{l}\text { Spigot flow } \\
\text { rate }\left(\mathbf{m}^{3} / \mathbf{h r}\right)\end{array}$ \\
\hline Minimum & 59.7 & 0.0213 & 10.0 & 119 & 2.67 & 34.1 \\
Maximum & 64.8 & 0.0540 & 34.0 & 170 & 2.84 & 53.2 \\
Average & 62.6 & 0.0379 & 21.4 & 139 & 2.75 & 44.9 \\
\hline
\end{tabular}

Table 2 Measured beach slopes from the Centinela trial

\begin{tabular}{llll}
\hline \multicolumn{3}{c}{ Average beach slope \% } & \\
& Before trials & Mid-October 2013 & End of trials (early November 2013) \\
\hline Profile 1 & $1.07 \%$ & $2.48 \%$ & $2.75 \%$ \\
Profile 2 & $0.98 \%$ & $2.55 \%$ & $2.96 \%$ \\
Profile 3 & $1.82 \%$ & $2.37 \%$ & $2.82 \%$ \\
Profile 4 & $1.82 \%$ & $2.86 \%$ & $2.93 \%$ \\
Profile 5 & $1.89 \%$ & $2.91 \%$ & $3.11 \%$ \\
\hline
\end{tabular}

The average beach slopes at the end of the trial are relatively consistent, notwithstanding the variability in the discharge and are of the order of $2.9 \%$. However, beach modelling carried out using laboratory-developed rheology indicated a beach slope of $2.5 \%$ - i.e. an underestimate. Again, it was clear that something was not being considered in the beach modelling. 


\section{$5 \quad$ Further development - incorporation of settling characteristics}

The Osborne and Centinela data were indicating a higher rheology than was being measured and, after consideration, this was attributed to the fact that slurries flowing under laminar flow conditions as those that occur down the beach, are prone to settling under gravity within the flow channel. Gravitational settling results in the concentration being higher at the base of the channel than at the top. Settling can be in combination with gravitational segregation where the particle size distribution at the base of the channel is coarser than at the top if the slurry is segregating. Gravitational segregation is more prevalent in slurry concentrations below $55 \%$ but depends on the particle size distribution of the tailings. The effect of settling is illustrated in Figure 6. Since deposition in the channel occurs at the base of the channel, in the depositing bed face, it is the rheology of this higher concentration that is dictating beaching characteristics.

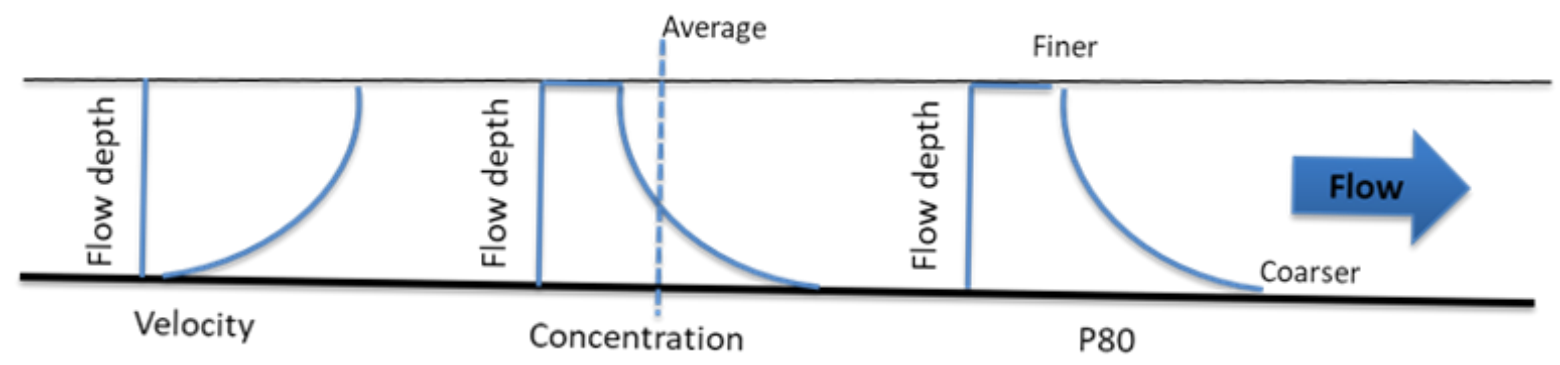

Figure 6 Effects of slurry settling

To measure the above, a fluidised bed column test has been developed, as described in McPhail et al. (2016). The test set-up is indicated in Figure 7.

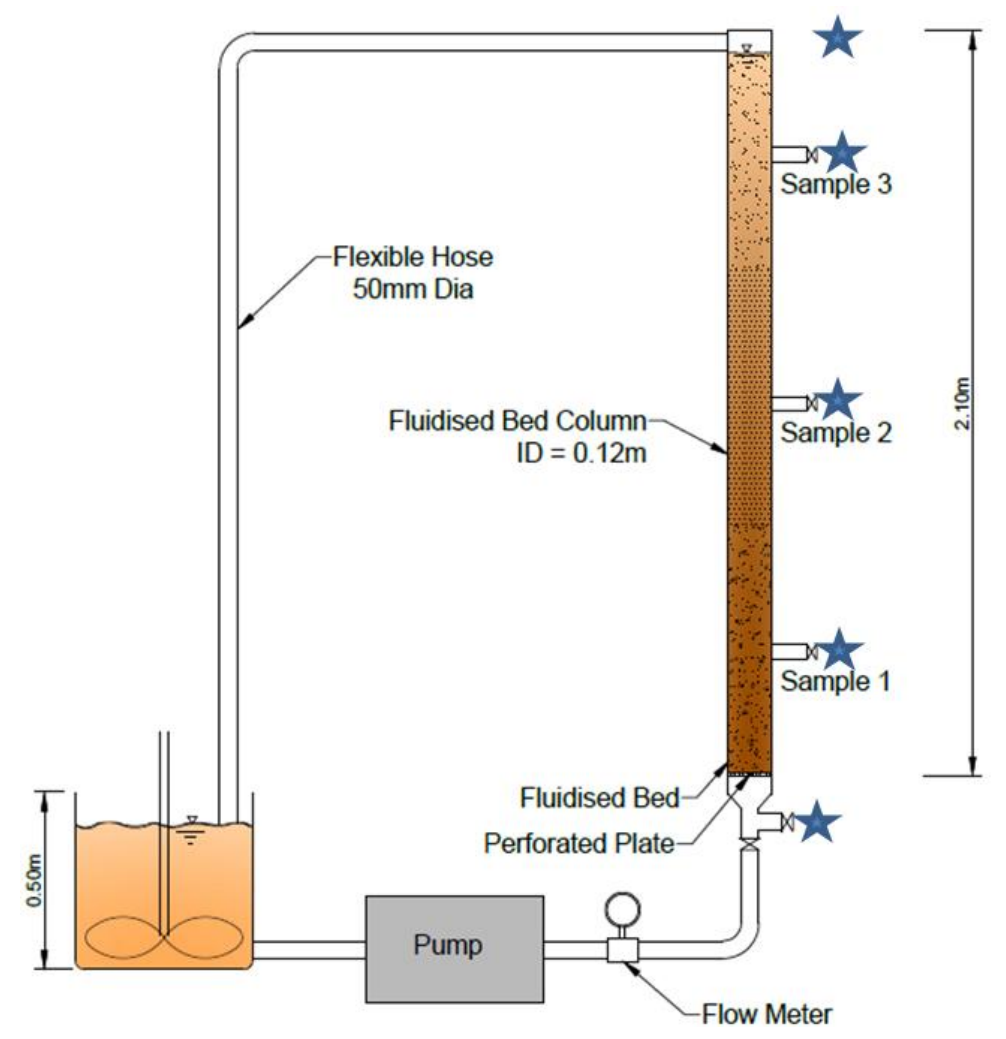

Figure 7 Fluidised bed column test set-up 
The principles of the test are as follows:

- Energy loss down a beach occurs due to frictional and viscous forces.

- Energy loss can be accelerated by gravity - it is a non-intrusive energy dissipator.

- Energy is scalar - it is the same in all directions, therefore, the energy loss can be simulated in a vertical column.

- On this basis, it is possible to simulate a $500 \mathrm{~m}$ beach in a $3 \mathrm{~m}$ vertical column.

The tailings slurry is circulated up the column until the slurry reaches equilibrium. As the slurry flows up the column, it loses energy and therefore loses the capacity to maintain particles in suspension. Where gravitational segregation occurs, heavier particles become suspended at lower elevations in the column. The stream power in the column is given by Equation 5:

$$
P=\rho g Q H
$$

where:

$$
\begin{aligned}
& P \quad=\text { the stream power at elevation } \mathrm{H} \text { up the column. } \\
& \rho \quad=\text { the slurry density. } \\
& g \quad=\text { gravity. } \\
& Q \quad=\text { the flow rate up the column. }
\end{aligned}
$$

By sampling at various points up the column (indicated with a start symbol) it is possible to correlate the slurry characteristics of the sample with stream power. Typical output from the column test for percent solids is indicated in Figure 8.

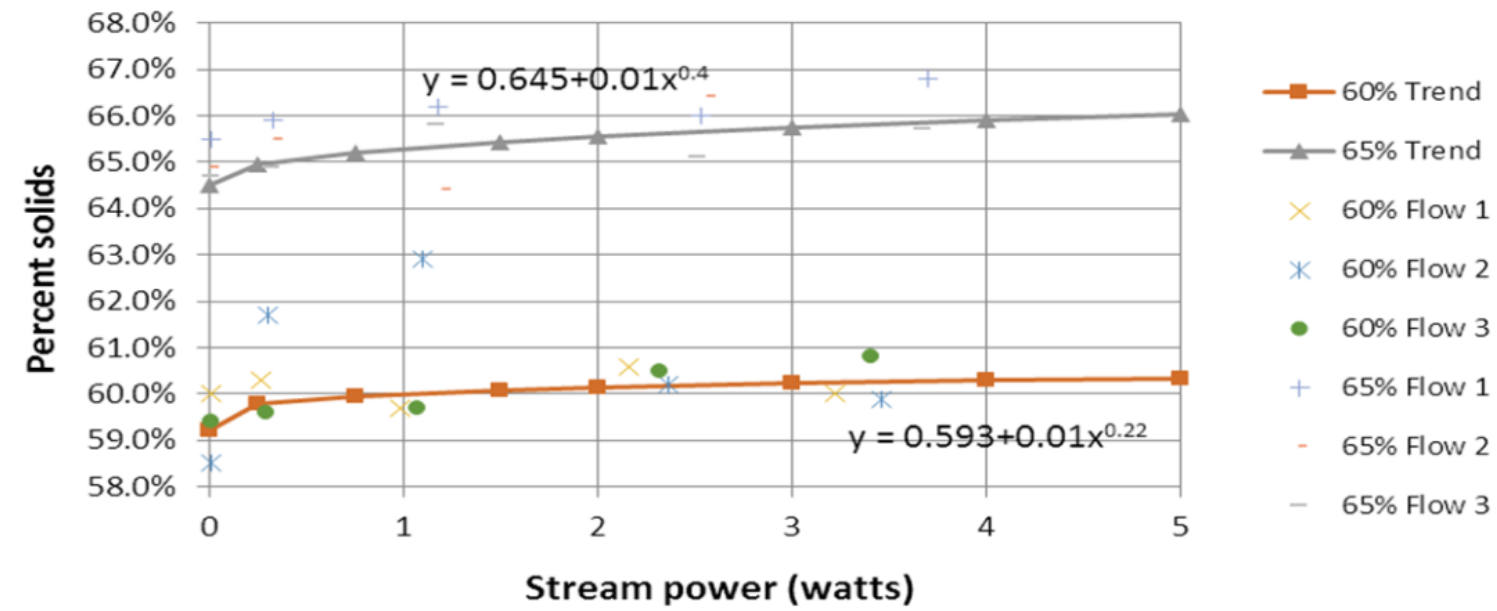

Figure 8 Typical percent solids (by mass) versus stream power curves from the column test 
By measuring the rheology of the samples, it is possible to correlate rheology with stream power as well and, since the stream power-entropy method calculates the stream power down the beach, it is possible to incorporate the actual rheology and percent solids at the depositing bed face down the beach as illustrated in Figure 9 where the column data is applied at the star symbol locations.

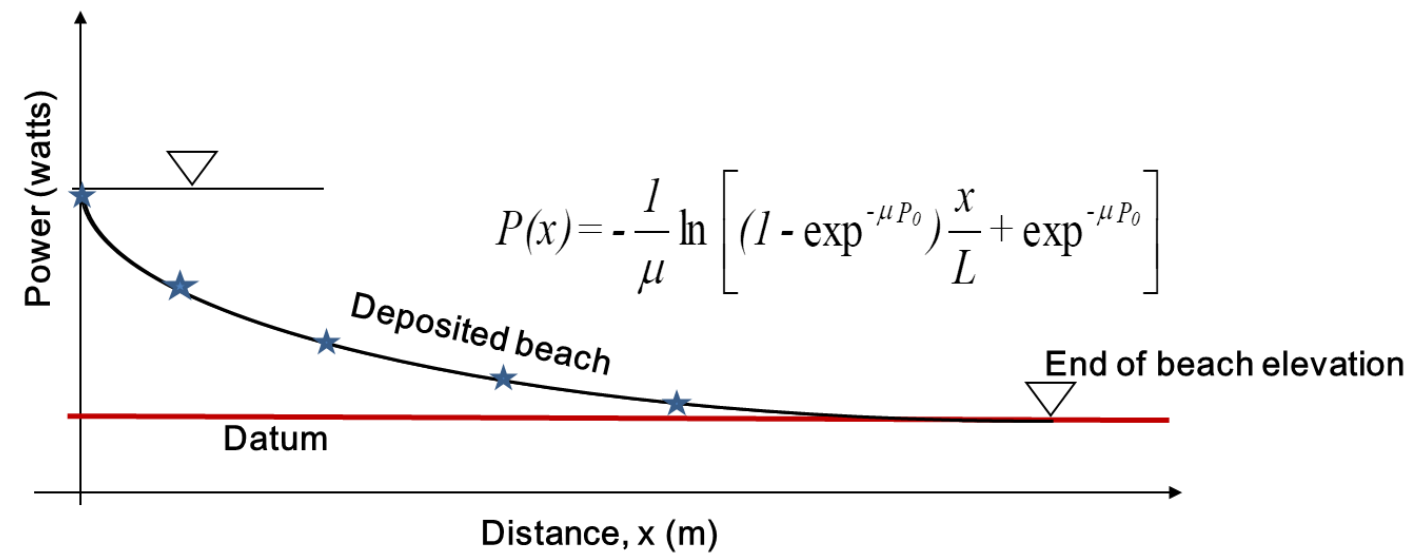

Figure 9 Application of the column data in the beach modelling

It is important to note that since the material depositing at the bed face is at a higher concentration than the average for the slurry at any point, the solids entrain less water than the average so the concentration of the slurry in the flow stream progressively reduces with distance down the beach. This is the reason the curves in Figure 8 trend downwards as stream power reduces.

\section{Comparison of field data with modelling that incorporates column-based settling characteristics}

Centinela mine went on to implement a full industrial-scale trial and have been operating this trial since 2015 during which time the multiple small stepped paddocks that were being constructed to 'stack' tailings in the upper parts of the beach were progressively covered. Since 2015, tailings production rates have progressively increased from 86,000 to 105,000 tpd and the slurry concentration has progressively increased from $62 \%$ solids by mass to almost $65 \%$ solids as new thickeners have been brought on stream. A comparison of modelled and actual beaches was carried out in 2016 using the original laboratory-based rheology, as well as the fluidised bed column test data. The rheological data is indicated in Figure 10 and the column test data in Figure 8. Discharges are at $60 \mathrm{~m}$ centres and at the time of the comparison the slurry was being discharged at an average of $63.7 \%$ solids. Figure 11 shows a satellite photo of the TSF and the location of the spigot header pipe with 12 spigot discharges.

Figure 12 shows the measured and stream power-entropy modelled beach profile for a section down the beach. In modelling, the beach settling has been included together with changes in slurry concentration and rheology down the beach based on the calibrated interpolated curve indicated in Figure 13. 

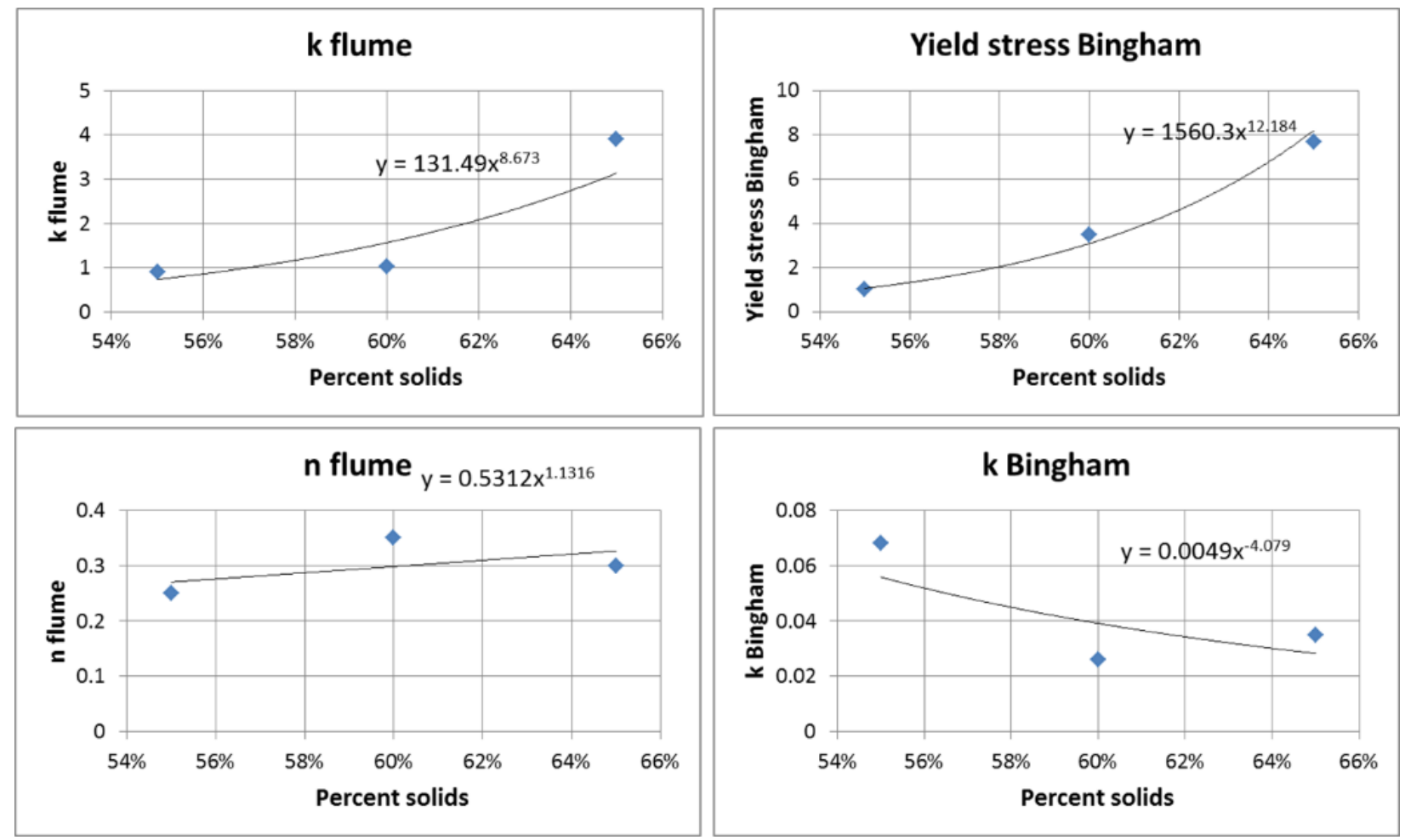

Figure 10 Lab-based rheology for Centinela
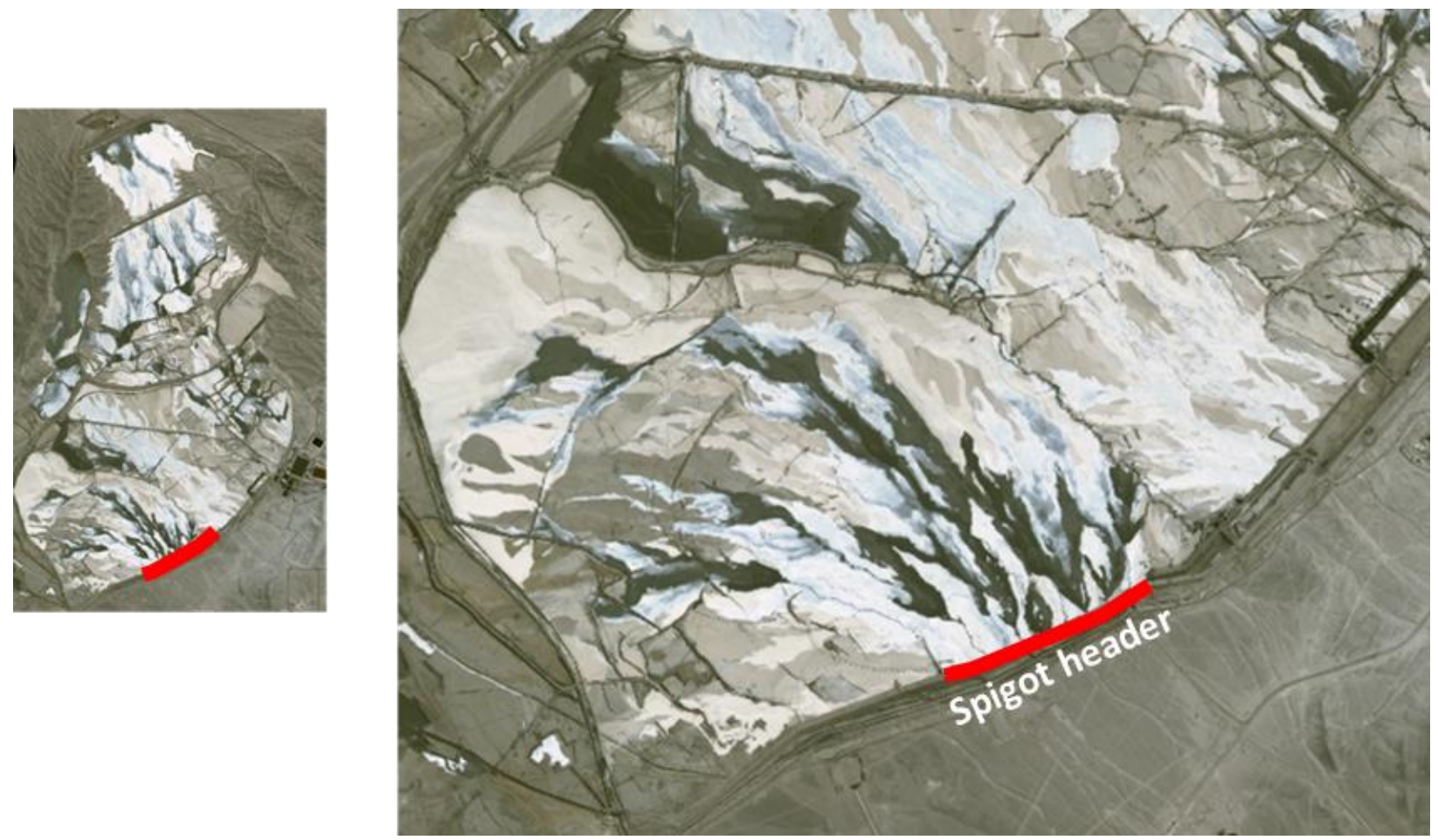

Figure 11 Satellite photo of the full-scale trial beach 


\section{SECT 2 AUG 16 CALIBRATION}

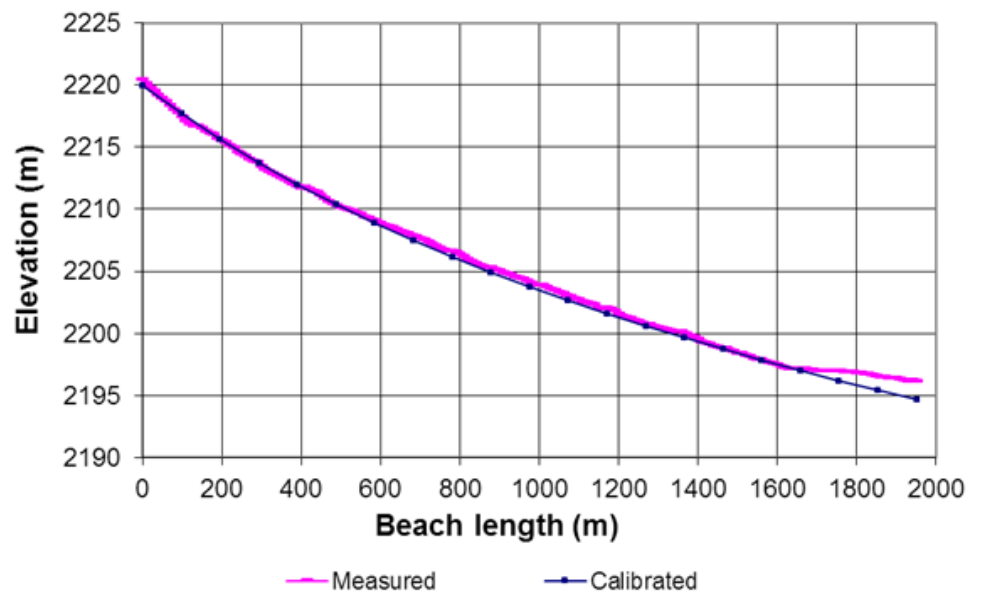

Figure 12 Modelled and measured beach profile at Centinela

\% SOLIDS VS STREAM POWER: CALIBRATED SECT 2

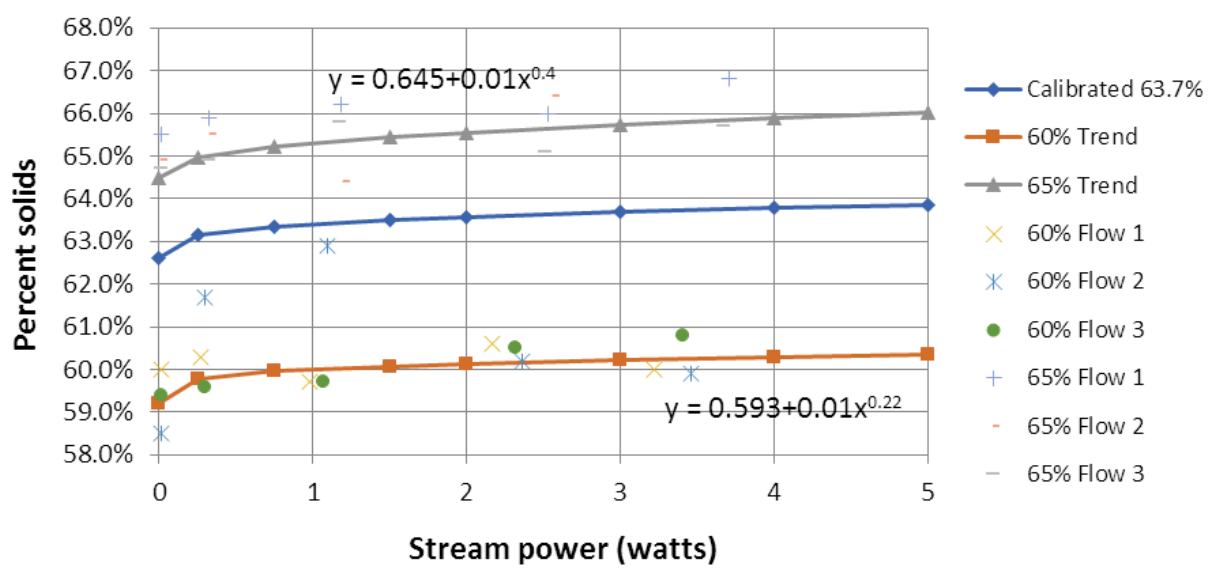

Figure 13 Calibrated/interpolated column test data

It is evident from Figure 12 that the fit between the modelled and the measured beach profiles is good, indicating that incorporation of settling into the modelling process is a significant improvement.

\section{$7 \quad$ Spigots and spigot spacing}

Tailings engineers have known for many years that one way to steepen a beach without changing rheology is to split the flow into a number of smaller flows, usually by means of a header and multiple spigots. The reason this is effective, provided the flow streams from the spigots do not re-combine, is because the smaller flow streams have higher shear resistance. As the flows reduce the shear resistance per unit of flow increases - witness the difference splitting the flow in one large pipe into two flows in two smaller pipes. The wall length per unit volume of slurry increases and therefore so does the shear resistance. Higher shear resistance implies higher shear stress. In beaching flow streams, the higher shear stress translates directly into a steeper beach slope. This phenomenon was confirmed in the semi-industrial-scale trial at Centinela where the beach was steepened from $0.9 \%$ to close to $3 \%$, simply by reducing the flow rate.

At Centinela, the decision to opt for $60 \mathrm{~m}$ centres for the spigot discharges to minimise the probability of flow streams combining, thereby flattening the beach, was based on educated guesswork combined with the physical limitation of the header pipe length. There were other spigot system locations to design and the issue of an appropriate methodology for defining spigot spacing required detailed consideration. 
The author has developed a random walk approach to the modelling of flow stream meanders (McPhail 2015) and is in the process of further improving on this approach.

The random walk process, when applied to beaching, entails the following:

- The spacing between the spigots is split into several equal lengths which become the length and width of an imaginary grid over the area of beach that will be influenced by the spigot header and spigots.

- A random generator is applied to determine for each spigot whether the flow meander will turn left by the next grid point or right.

- This process is repeated down the beach so that a set of randomly generated flow paths are derived for all the spigots. These represent a point in time.

- Where flows intersect, they are combined so that, depending on the spacing, the number of independent flows moving down the beach reduces in proportion to the combinations.

- The process is repeated many times and the probability of flows combining with distance down the beach is determined.

Examples of the resulting flow patterns for a range of spigot numbers are provided in Figures 14 and 15.
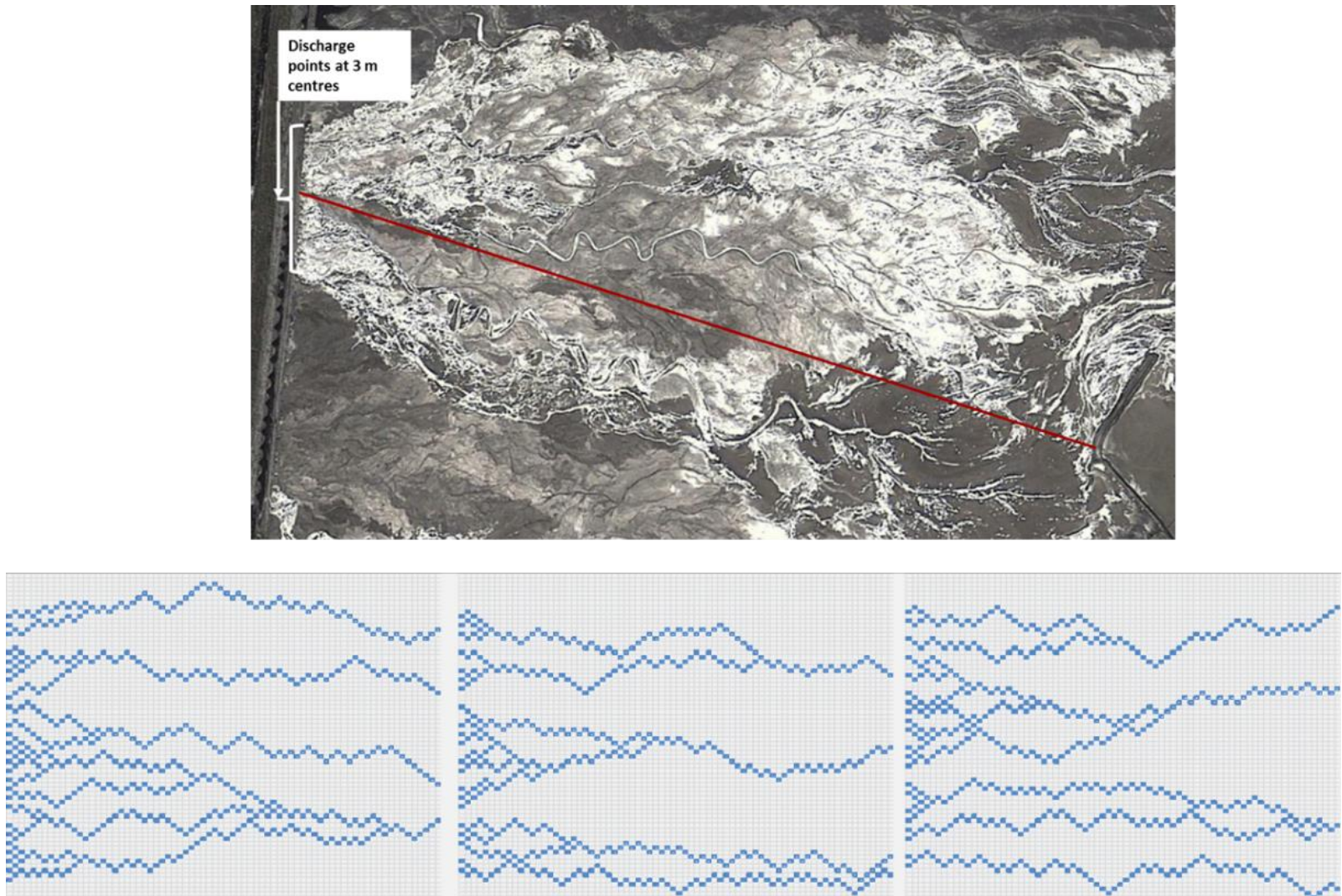

Figure 14 Comparison with the actual of modelled meandering flows with spigots at $3 \mathrm{~m}$ centres based on the random walk approach 


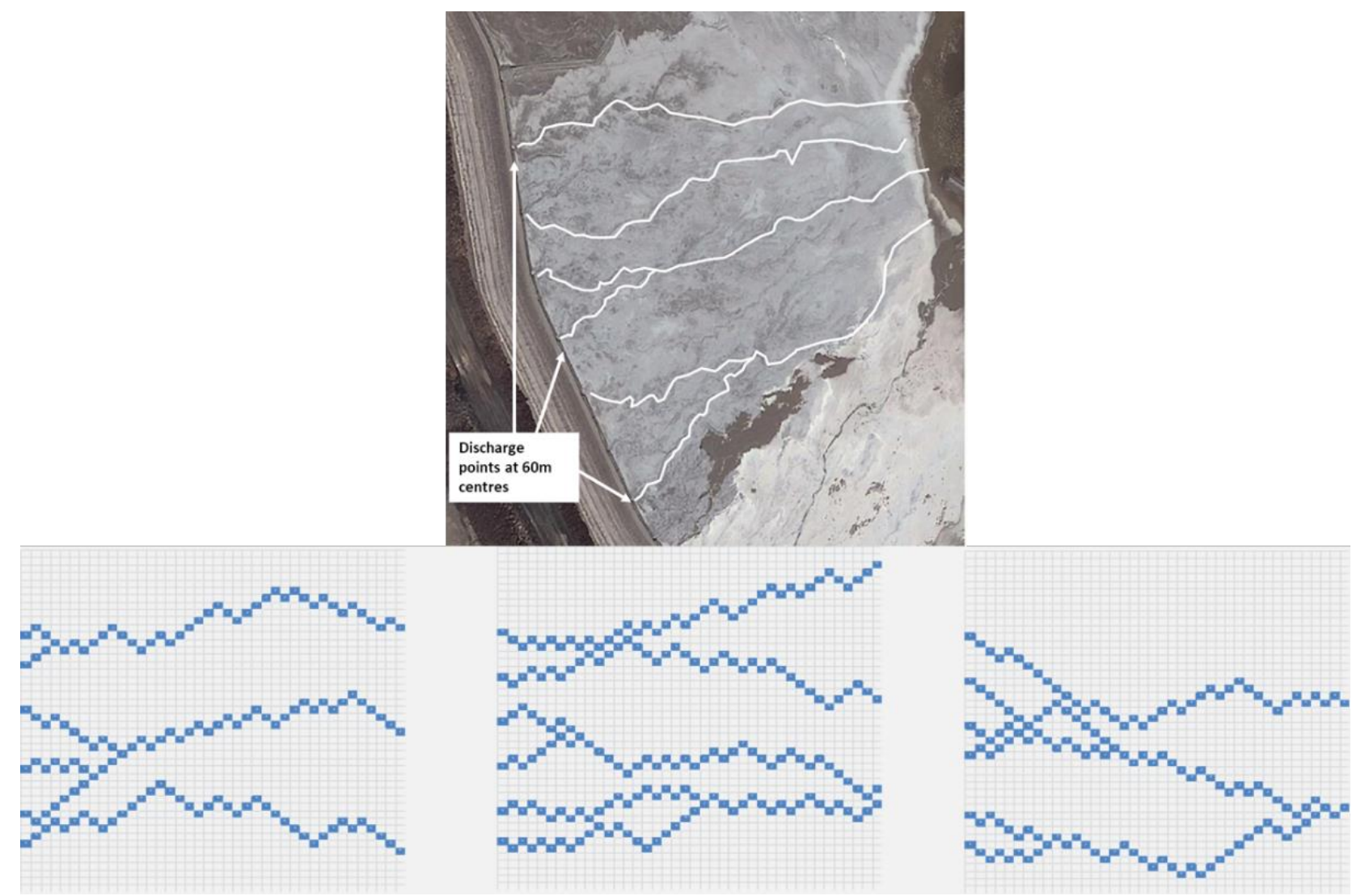

Figure 15 Comparison with the actual of modelled meandering flows with spigots at $60 \mathrm{~m}$ centres based on the random walk approach

It is evident that the random walk approach has merit.

\section{Application to Sierra Gorda}

The most recent application of the approaches described so far in this paper that allows some comparison with actual is at Sierra Gorda mine in Chile. This mine produces tailings at some 130,000 tpd and up until 2016 was being operated with a single discharge producing a beach of $0.5 \%$. Since this is flatter than the topography, the tailings were all flowing directly down to the main confining embankment and building up from there. Sierra Gorda was keen to limit the rise of the embankment by increasing the stacking of tailings closer to the discharge point and opted for spigot discharge as the means to achieve this.

Testing, as described previously, was carried out over two programs - one in 2016 and one at the end of 2017. The latter program included column tests.

During the spigot discharge design, care was taken to limit the flow rates in the spigots to achieve a beach steeper than the natural ground slope. Modelling in this respect was carried out in conjunction with random walk modelling over the planned beach length and it was decided to position the spigots at $55 \mathrm{~m}$ centres. The length of spigot header pipe was dictated by the width of the site which meant that the number of spigots at this spacing was limited to 24 split over two simultaneously operating headers. The spigot flow limitation meant that under certain circumstances, flow in excess of the specified spigot flow had to be discharged through open ends at the ends of the spigot headers. In cases where the open end flows are higher than the spigot flows, they will tend to beach flatter than flows from the spigots and the flow streams will cut into the beach. This was regarded as acceptable as the spigot flows would control the degree of cutting.

Headers have been commissioned in stages, with the final set out of four only recently completed. In addition, there have, since commissioning the first header, been many occasions where Sierra Gorda has 
found it necessary to discharge the full flow stream bypassing the headers. During these times, the flows go directly to the confining embankment, flattening the beach near the embankment. There are, however, lengths of beach that allow some degree of calibration.

Figure 16 shows a plan of the TSF and the locations of the sections that have been analysed. Figure 17 shows the section details from which the influence of the single point discharge on the beach closer to the confining embankment can clearly be seen by the bi-modal shape of the beach profile.

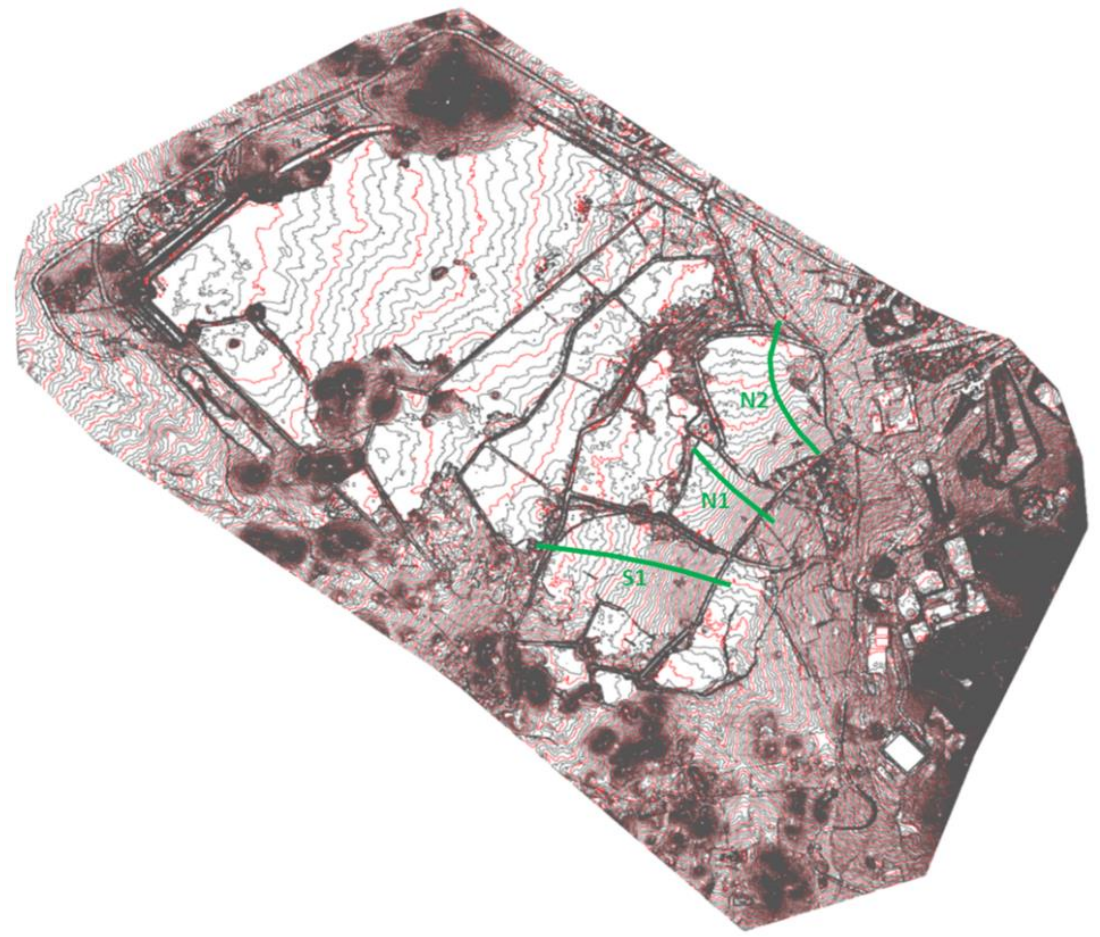

Figure 16 Plan of the Sierra Gorda TSF showing sections analysed

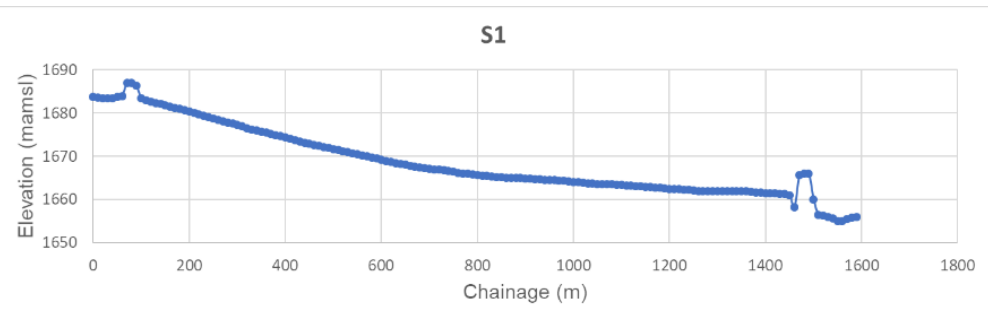

N1

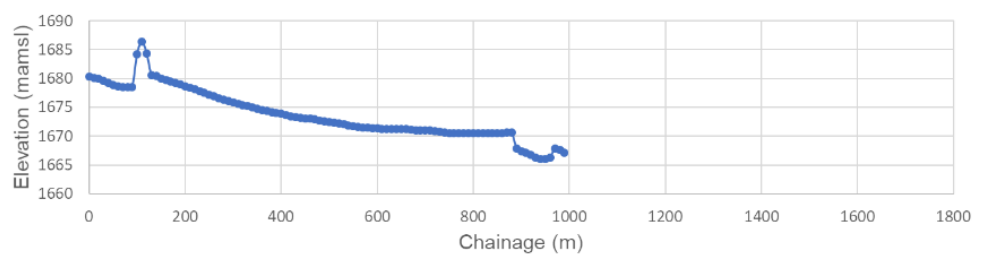

N2

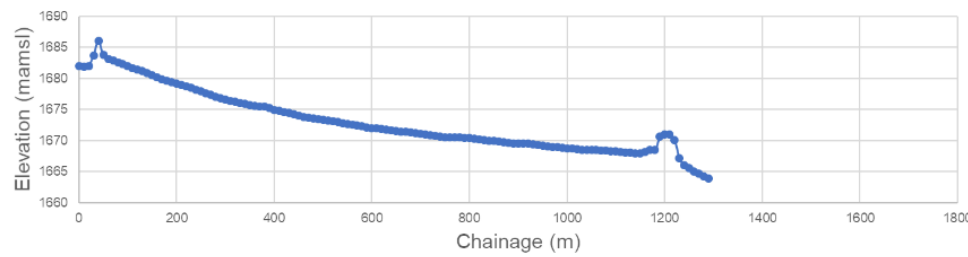

Figure 17 Sections analysed 
Figure 18 shows the modelled and measured sections after calibration of the percent solids versus stream power curve. This emerges as steeper than that measured in the fluidised bed column testing. The difference is ascribed to short circuiting during the column testing because of the sampling flow rates being some $80 \%$ of the total flow rate. The measured and calibrated curves are indicated in Figure 19.
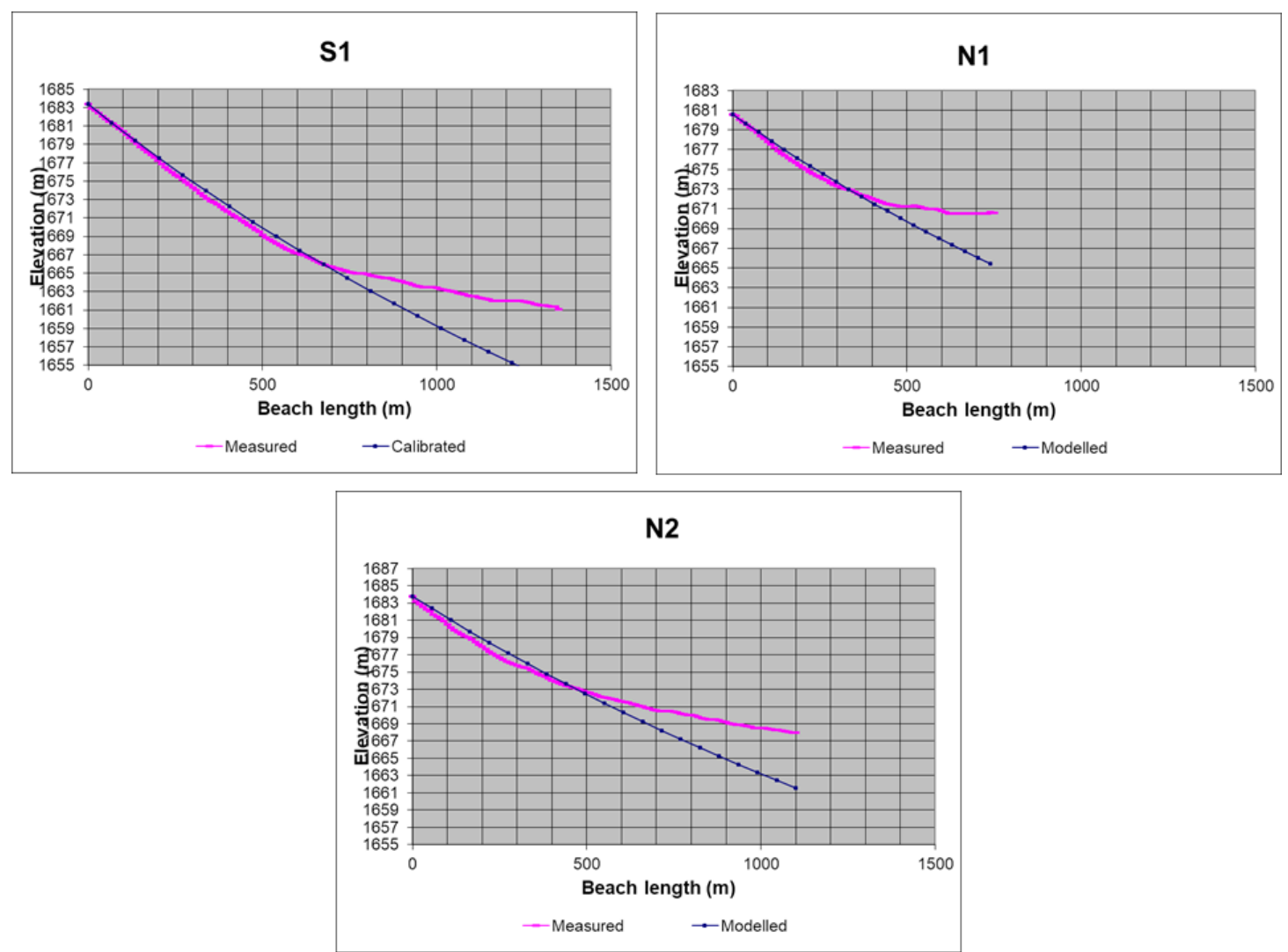

Figure 18 Comparison of modelled and measured profiles

\section{\% SOLIDS VS STREAM POWER}

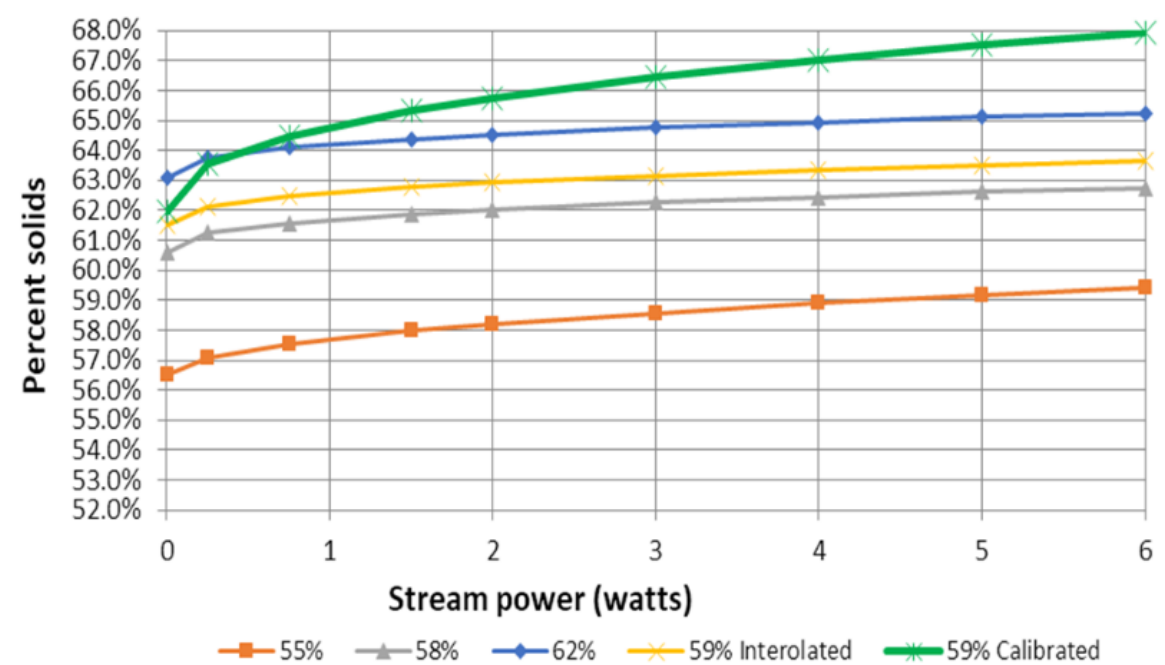

Figure 19 Measured and calibrated curves of percent solids versus stream power 
It is evident that the modelled beach profiles are within reasonable agreement with the measured profiles, allowing for the single point deposition. Since the modelling is based on independent flows from the spigots, the good correlation between modelled and measured profiles suggests that the spacing of spigots is effective in controlling the extent to which flow streams combine. This is further evident from the latest satellite photos.

\section{Summary and conclusion}

This paper documents the current state-of-the-art with respect to application of the stream power-entropy approach to beach profile modelling and prediction. The nature of tests developed to provide reliable rheological data, as well as the specific characteristics of the tailings slurry at the bed face down the beach, has been described. The way comparison with field data has been instrumental in driving continued development of the approach has been highlighted.

It is clear to the author that the stream power-entropy approach has significant merit. It is capable of handling mine production rates from 4,000 to $130,000 \mathrm{tpd}$ and a range of slurry rheologies and consistencies. Moreover, it is capable of modelling small-scale flumes of less than $0.5 \mathrm{~L} / \mathrm{s}$ flow rate and beach lengths of less than $2 \mathrm{~m}$, and forms the basis of deriving rheological parameters from small-scale flume rheometer tests.

But the refinement of the approach and the testing methods to provide appropriate data for modelling using the approach continues, although it can be safely stated that the need for this refinement is steadily reducing.

\section{Acknowledgement}

The author acknowledges Dr Jon Engels of Tailpro Consulting, Chile. Jon has been key to the development of the flume rheometer and the fluidised bed column by listening to wild ideas, assisting with the design of the testing the equipment, and finally implementing the laboratory testwork. The author also acknowledges the invaluable contribution Osborne, Centinela and Sierra Gorda mines have made to the furthering of the stream power-entropy development by believing in the approach, funding testwork, and providing field data for predicted versus actual comparisons. Finally, the author acknowledges the input of peers and colleagues, notably those within the Australian Centre for Geomechanics.

\section{References}

Bentel, GM 1981, Some Aspects of the Behaviour of Hydraulically Deposited Tailings, MSc thesis, University of the Witwatersrand, Johannesburg, pp. 1-145.

Charlebois, LE, McPhail, Gl, Revington, A \& van Zyl, D 2013, 'Observations of tailings flow and application of the McPhail beach profile model to oil sands and metal mine tailings', in GW Wilson, DC Sego and NA Beier (eds), Proceedings of Tailings and Mine Waste 2013, University of Alberta Geotechnical Centre, Edmonton, pp. 169-180.

Jaynes, ET 1957, 'Information theory and statistical mechanics', Physical Reviews, vol. 106, pp. 620-630.

Kapur, JN \& Kesavan, HK 1992, Entropy Optimization Principles with Applications, Academic Press Inc, San Diego.

Küpper, AMAG 1991, Design of Hydraulic Fill, PhD thesis, University of Alberta, Edmonton, pp. 1-524.

McPhail, GI 1995, Prediction of the Beaching Characteristics of Hydraulically Placed Tailings, PhD dissertation, University of the Witwatersrand, Johannesburg.

McPhail, GI 2015, 'Simulation of the meandering flow path of a beaching slurry using a random walk technique', in RJ Jewell and AB Fourie (eds), Proceedings of the 18th International Seminar on Paste and Thickened Tailings, Australian Centre for Geomechanics, Perth, pp. 467-475.

McPhail, GI, Engels, J \& Ugaz, R 2016 'Application of fluidised bed column testing to the assessment of beaching and segregation characteristics of mine tailings', in RJ Jewell and S Barrera (eds), Proceedings of the 19th International Seminar on Paste and Thickened Tailings, Gecamin, Santiago.

Shannon, CE 1948, 'A mathematical theory of communication', The Bell System Technical Journal, vol. 27, no. 3, pp. 379-423, https://doi.org/10.1002/j.1538-7305.1948.tb01338.x

Thomson, RR 1984, Depositional Characteristics of Tailings as Observed from Laboratory Studies, MSc degree, University of the Witwatersrand, Johannesburg, pp. 1-75. 